Session 2793

\title{
Using Technology to Enhance and Expand the Learning Environment in a Lower Division Computer Engineering Course
}

\author{
Richard Freeman, Rebecca Sidler Kellogg \\ Iowa State University
}

\begin{abstract}
During the summer of 2001 the lower division computer engineering course at Iowa State University (ISU), Introduction to Digital Design, was restructured to leverage instructional technology, incorporate multimedia, and reach a geographically diverse group of learners. A faculty member from Computer Engineering partnered with Engineering Distance Education to take this unique opportunity to explore how we could teach this course more effectively.

Innovative use of technology and media impacted not only what we were able to do in the lecture, but also the laboratories that are part of part of the course. The lectures were captured digitally and made available using streaming video. This gives students flexibility in viewing lectures multiple times as they learn. Before this, students only had the option of viewing the content in a synchronous mode. One of the other powerful advantages of using technology was the ability to bring examples from the real world into the classroom. For example, in discussing finite state machines the instructor did a remote session in front of a vending machine, which illustrated the concepts using something students interact with often. In reconsidering the laboratory experience, the focus was on addressing the issues related to providing hands-on experiences to distance students. Addressing these issues for off-campus learners also had positive implications for the large on-campus student body in computer engineering. An example of a change to the course lab, which will discussed later.

The lecture and laboratory instruction as well as the communication between faculty and students for this course was done exclusively using a web-enhanced environment including streaming video and WebCT. Use of the Web enabled ISU to offer this course to a wider audience as far away as Puerto Rico. Before, due to technology restrictions, this undergraduate course was only available to a limited number of sites within the state of Iowa. ISU has a successful BSEE program available to off-campus students and is now carefully examining the feasibility of expanding this program beyond the state. These efforts have helped us identify the issues related to doing so.
\end{abstract}

After the positive experience of reformatting Introduction to Digital Design, we were asked to develop a version of the course for in-service 8-12 teachers as part of a NSF grant awarded to ISU. This opportunity raises some other interesting challenges in dealing with a wider range of

"Proceedings of the 2002 American Society for Engineering Education Annual Conference \& Exposition Copyright (C) 2002, American Society for Engineering Education” 
technologies and learners with different backgrounds and needs. There is no doubt that as we continue to think through and develop this course, there will be feedback to the Introduction to Digital Design course as well as the possibility of a large secondary audience of junior and senior high school students and teachers.

Introduction

In 1996, ISU and Kirkwood Community College (KCC) began offering a distance-based Bachelor of Science degree in Electrical Engineering (dBSEE). This degree program offered students the opportunity to take foundation and non-technical courses in mathematics, sciences, and social sciences and humanities, as KCC students, at KCC. Faculty taught core dBSEE courses in Electrical and Computer Engineering from ISU's Department of Electrical and Computer Engineering.

Since the inception of the degree program, ISU faculty has utilized the services of Engineering Distance Education (EDE) and the Iowa Communications Network (ICN) to teach classes to students in Eastern Iowa. The ICN has over 800 connected locations around the State of Iowa. $\mathrm{KCC}$, like ISU, has multiple classroom and conference room connections. The ISU Extension Service Office, at KCC, and EDE work together to provide classroom services, test proctors, and support services to both dBSEE students and faculty. In addition, KCC has provided facilities for lab activities.

ISU was responsible for hiring its own laboratory instructors for the labs. The lab portions of classes are scheduled around the availability of instructors and students. This usually means that labs are held on the weekends, evenings, and/or during extended lunch hours. Since the majority of the dBSEE students are fulltime employees, there is more flexibility in scheduling labs, tests and homework due dates. As part of the dBSEE program, ISU provides and maintains laboratory equipment and software.

The ICN has been the main medium for delivery of courses to dBSEE students. This unique network allows video teleconferencing, broadcast, and data communications. Since the ICN is a shared resource, classes must start and end on time. The resource allows for students at each of the Regents Institutions to participate in courses not physically offered at their locations. EDE videos each class session, and, at the instructor's request, will put these videos available for students to review. For dBSEE students copies of the class sessions were typically available through the Extension Office at KCC. Beginning in the Fall of 2001, EDE began videostreaming the sessions and digitally archived lectures. Since EDE uses the WWW to deliver these sessions, $\mathrm{dBSEE}$ students have access to the lectures throughout the semester.

\section{Computer Engineering 210}

CPR E 210- Introduction to Digital Design is the first core course for dBSEE students. This course is an introduction to foundation topics in Computer Engineering. Topics such as binary and hexadecimal numbering systems, Boolean Algebra, sequential and combinational logic, data paths, and instruction set design are introduced to students. The target audience is composed 
mainly of Computer and Electrical Engineering and Computer Science students. The course may also be used as a technical elective for some other engineering majors.

CPR E 210 has an integral lab component as part of the course. Students utilize simulation and Computer Aided Design tools to complete exercises that support topics covered in lecture and homework. Lab exercises are designed for the students to gain a deeper understanding of the course material through "hands-on" activities. Students must apply concepts introduced in lecture and reinforced in homework exercises. ISU invested in computers, peripherals, and software for both on- and off-campus students. Changes in laboratory equipment and exercises for on-campus students are introduced within one semester to dBSEE students. The goal is to maintain consistency in the course material for both groups of students. One of the primary goals of the department faculty is that the dBSEE be the same degree as the BSEE earned oncampus.

CPR E 210 is a regular course offering. It is one of the few core courses offered to dBSEE students during an eight-week summer session. For all students, the course meets five days a week for one hour. The on-campus students are also assigned to a two-hour lab section that meets twice a week. The dBSEE students work with the lab instructor, in Cedar Rapids, to complete the labs in a timely manner.[1] Since the course has an integrated lab component, falling behind in the labs lessens their effectiveness and frustrates the students. The course structure had essentially been unaltered since its creation.

During the summer of 2000, CPR E 210 was opened to dBSEE students outside of Cedar Rapids, IA. This marked a significant departure from providing the dBSEE program exclusively to students within driving distance of KCC or ISU. EDE was able to obtain ICN-equipped sites for everyone, but providing laboratory equipment for everyone was not feasible. Some students were forced to drive to either KCC or ISU for lab. In many cases, the dBSEE students lived more than one hour from either ISU or KCC. There was less flexibility in scheduling lab times for students, and usually meant that there were multiple lab sessions per week. Some of the dBSEE students drove to ISU, and completed multiple labs over four weekends. This situation was partly responsible for changes in perspective about how to deliver the BSEE Program.

\section{Course Evolution}

During the summer of 2001, EDE was ready to introduce new technology for delivering courses to distance students. EDE had acquired the licenses to become a Real ${ }^{\mathrm{TM}}$ Site. This meant EDE was able to develop and deliver streaming video content, with WebCT as thew course management tool. For students, this meant that courses would soon be available via streaming video, anytime, anywhere, as long as long as they had Web access. This new technology allowed ISU to more efficiently deliver the dBSEE Program classes to students distant from both ISU and KCC. The result was a course offered to one student at ISU, two students in Cedar Rapids (near KCC), one in West Des Moines (near ISU), one in Fort Dodge (near ISU) and San Juan, Puerto Rico. The addition of the student from Puerto Rico was the first National Technological University (NTU) student in the course. 
An on-campus student was a very important factor in delivering this course. The student, Jason Boyd, provided feedback- when he did not understand, or had questions, he was had to ask them in real time. Boyd also helped pace the lectures, and performed the labs as they were recorded. Boyd is an ISU employee who is working on his BSEE part-time. As a technician, Boyd is very familiar with the equipment, software and labs.

One of the significant factors when discussing technology in education is cost. Engineering Distance Education encompasses a substantial infrastructure of technology and personnel. The costs of the program are carefully scrutinized each semester. A main advantage of streaming media is the cost per site. The ICN, the fiber optic network connecting the classrooms, is heavily subsidized by the state of Iowa. Even so, it requires at least 6 students at each site to break even. Use of streaming video reduces this requirement to 2 students per site. As the program expands beyond one site in Cedar Rapids, streaming media becomes the only viable option from an economic point of view. EDE is currently delivery the dBSEE program to 4 additional sites in Iowa. Each site has only one or two enrollments. Thus, to continue to meet the obligation to the off-campus student, EDE continues to work to identify appropriate models of use for streaming video and delivery over the Internet.

The structure of the course has changed with the introduction of streaming video and WebCT. As with any asynchronous course, students can email, and call with questions. The advantage of WebCT is the ability to discuss questions and concepts in the Chat Area. This allowed the instructor and other students to answer questions and delve deeper into material. This interaction sometimes advances the lecture for the following class session. Given the backgrounds of the students, some asked and answered very advanced questions based on their own work experiences. This brought a unique and important dimension to the course not always present in the on-campus version.

During the summer of 2001, each class period began with the daily shot of campus. This became morning trivia- "Where was this image taken?" This technique was used to facilitate a sense of ISU identity in the off-campus learners. The instructor then answered questions that were posed in the instructor's email. Any homework, quiz, lab, or test issues were addressed next. Finally, the instructor began the lecture by quickly reviewing the material from the previous session. The use of streaming video eliminated the need to be concerned about rushing through student questions, since the precise start and stop times mandated by the ICN are no longer required. With the ability to review, stop, and rewind lectures, the instructor observed that the students tended to ask questions that indicated they were focusing more on the higher levels of Blooms Taxonomy.[2] Specifically, students asked more questions reflecting thinking at the synthesis and evaluation levels, rather than the comprehension level that is more common.[3]

The introduction of new delivery technologies also allowed the introduction of some new class content. An example is the use of a vending machine to demonstrate how digital devices (controllers) can be embedded into ordinary everyday objects. The demonstration also showed how Finite State Machines behave in the real world. As part of the course, the instructor modeled a vending machine as a Finite State Machine. The Next State Diagram was developed at the end of a lecture. During the following lecture, a remote session was filmed in a student lounge where EDE videotaped the instructor using several vending machines. As part of the

"Proceedings of the 2002 American Society for Engineering Education Annual Conference \& Exposition Copyright (C) 2002, American Society for Engineering Education” 
demonstration, the instructor explained how and when the machines switched states, and noted possible machine states. The goal was to get students to see how Finite State Machines represent and model Digital Devices that are part of their everyday lives.

The use of new technologies also allowed the instructor to more easily appeal to different learning styles. Felder's research in the various learning styles of engineering students suggests several techniques for addressing the needs of those learning styles. [4] For example, the use of Smart Board technology combined with the video production capabilities of EDE during labs enabled the instructor to discuss the particular objective of a lab step, review the theory, all while the students saw that theory put into use in the laboratory exercise. During particularly difficult lab exercises, the instructor could prepare in-depth discussions on how the lab related to course theory, and vice versa. Students could follow the streaming video step-by-step, or as their confidence in using the equipment and software grew, skip the tutorials. The use of video technology also meant EDE was able to videotape computer simulations in a window, while showing the instructor or diagram in another window. The goal was to put theory and concept next to simulations of real world applications.

Rethinking what we do

The lab component posed a major challenge. The original goal was to extend the existing method for labs into the new class environment. Equipment at $\mathrm{KCC}$ was due to be upgraded to match what was in use at ISU. ISU and KCC hired an employee of Rockwell Collins, and ISU Alumni, as a lab instructor for CPRE 210. She was hired based on the dBSEE needs per semester. The lab instructor was not familiar with the new arrangement, and was heavily involved with a project at work. This meant we would either have to remove the lab component of the course, or attempt a new method of delivering the labs. The decision was made to experiment with a new method of delivering the labs using the technology at our disposal.

To deliver a lab, we had the ICN, streaming video, and WebCT available to us. The decision was made to use these technologies together. We scheduled the first lab session to include the first two labs. Jason Boyd delivered and installed the new equipment and software at KCC. It was decided that he should stay at KCC and walk those students through the lab. The ICN and streaming video were scheduled also. The NTU student made arrangements to work on the lab exercises at work, so he could watch the stream and work on the lab. The two dBSEE students in the immediate area drove into ISU's campus, and met with the instructor. The goal was to give the on-campus and KCC students the opportunity to ask questions and provide feedback via the ICN, and have the NTU student view the labs live via streaming video and communicate via the chat feature in WebCT.

Unfortunately, the computer at KCC failed- crashing multiple times, and never allowing the students there to get the lab software running. The NTU student was unable to get the video from work- the firewall would not allow him to access the WebCT application from his office. After four hours, we decided that the attempt was unsuccessful. After all our efforts, we completed one lab exercise. 
The next attempt at lab exercises used just streaming video and the dBSEE students near Ames came again campus. We still sought to make this a synchronous event. The instructor led the labs, with Jason Boyd actually doing the exercises for the streaming video. Additional technical difficulties rendered this attempt at completing lab exercises a failure as well. The dBSEE students loaded the lab software at home, and would attempt to watch the streaming video and call in with questions via an 800 number. Several problems with the software arose, and two of the students were unable to keep up with the lab session. After a couple of calls to Technical Support, the problems were resolved. Trying to provide a synchronous was proving to be a problem.

The final attempt at providing a laboratory experience for CPR E 210 students was a success. This procedure was asynchronous. The first two attempts at lab exercises were based on doing what was normally done- this final attempt took complete advantage of the technology used to deliver that course. For the asynchronous method of lab delivery- Jason Boyd, the on-campus student, did the lab exercises for the video stream. The instructor was responsible for reintroducing the theory required for completing the labs. The dBSEE students were instructed to complete the labs, and email their files for evaluation. Since the lab exercises involved simulation software, most of the exercises were easy to evaluate. In addition, as students had problems with labs, they could email their files, and advice could be given. This method allowed for students to complete labs at a faster pace, on their own time, and gain a much deeper understanding of the course material.

\section{ABET considerations}

During the 2001 academic year, the College of Engineering at Iowa State University underwent ABET evaluation. As part of the evaluation, the BSEE degree offered to off-campus students was evaluated along with the traditional on-campus degree program. The evaluation team carefully examined the delivery system, with one member traveling to the Cedar Rapids site. While at the Cedar Rapids site, the team member was able to interact with the off-campus students and see the facilities. In addition to the delivery system, the team examined the design projects and laboratory delivery. The latter issue, laboratory components of degree programs, is currently under study by the ABET Board.[5]

One of the more important points to emphasize is that a study of student outcomes for both the on and off-campus students conclusively demonstrated that there was no significant difference between the two. This is consistent with most studies that examine student outcomes of distance education programs. One would not expect a significant difference in the traditional delivery methods used up until summer 2001. The students at the remote site were largely receiving the same content using the same teaching methods. Students were receiving a two-way interactive course using a system that enabled simultaneous exams as well as opportunities for questions in real time. With the new version of Computer Engineering 210, the teaching methods and use of media were substantially revised. Additionally, streaming video was introduced. As discussed in this paper, the video stream offers students only limited opportunity for synchronous interaction, but provides them 24-7 access to view and review the lecture content. It is important to determine how the new version of Computer Engineering 210 and its new delivery mode impact student learning outcomes. Such analysis has yet to be completed. 
Future impacts

The immediate impact to Computer Engineer 210 has been a change in lab equipment. The experiment of a true distance version of the course caused the department to examine what was necessary for lab. Computer Engineer 210 for the fall 2001 semester did not use a simulation board. Circuit Maker Software simulations replaced the first three labs, and the remaining lab exercises used the Altera Max II Plus Software for simulation. The Altera Simulation Board was assigned to an advanced computer architecture course. The initial reaction to key departmental faculty was favorable. The sentiment that the "hands-on" lab experience for students at this level was necessary had passed. As noted by Bourne et al, this "experience has ceased to exist in some disciplines."[6] For the students in the ISU BSEE and dBSEE Programs, the experience of wiring a simulation board to simulate a simulation is not necessary at this level. Furthermore, ISU's program replaced "hands-on" experimentation and laboratories when the course directors replaced CPRE 280 (Digital Design) and CPRE 281 (Digital Design Laboratory) with CPRE 210 using MACABLE and PEELs approximately ten years ago.

Another immediate impact has been the development of a short course for 8-12 Mathematics and Science teachers. This is part of an NSF grant to help teach engineering concepts to 8-12 teachers. The goal is a series of short courses helping teachers integrate topics of digital design into their curriculums. While the use of streaming video and WebCT may not be the best solution (given some of the PC and bandwidth problems in some schools), the same general techniques developed during the class can be applied to CD-ROM and on-campus delivery of the short courses.

The long-term impacts to the course are just beginning to be considered. One option available to the department is to make the course available online to on-campus students. This means lectures would be available via WebCT and streaming video. The course would have a recitation with Teaching Assistants, and the instructor would have a lecture/help session one to two times per week.

Virtual labs are another option yet to be considered. The department must currently provide technical support to dBSEE students using the current software. This can be problematic in cases where students are trying to install or use the software at their workplace. The virtual lab would eliminate the need for off-campus and on-campus students to worry about anything more than having access to the Web. While the virtual lab environment provides its own set of challenges, it would eliminate the need for department technicians to handle technical support. Electrical Engineering 201, Introduction to Circuit Analysis (EE 201) has been using software developed at University of Illinois, called Mallard ${ }^{\mathrm{TM}}$ for several years with few problems. All EE 201 students log into Mallard ${ }^{\mathrm{TM}}$ to study for tests, complete homework assignments, and quizzes. Mallard is a Web-based learning tool for delivering course material and assessment.[7]

"Proceedings of the 2002 American Society for Engineering Education Annual Conference \& Exposition Copyright (C) 2002, American Society for Engineering Education” 


\section{Conclusions}

The use of technology has pushed the boundaries of what was thought possible for teaching CPRE 210. While the use of the technologies has not been fully explored or utilized, the ability to provide anytime, anyplace delivery of course content deserves careful consideration. The technology may yield the ability to provide the capability for students to earn course credit, and ultimately a BSEE from anyplace with Internet access.

While some may find the technology intrusive, it proved very liberating in this course. Instructors have the ability to bring new tools, ideas, and teaching methods into the classroom. The ability to generate and incorporate demonstrations from outside the classroom is an exciting prospect. The technology allows instructors to teach to virtually any learning style. As stated by Kashy et al, "the technology can have a profound impact if it is used in a way that capitalizes on its unique ability to 'interact' with students... and facilitate interactions among students and between students and teaching staff." [8] The technology does require the instructor to work closely with a trained and competent production staff, to plan out how and what can be incorporated into a lecture. This does require the instructor to think about whether doing what has been done, has more impact than what can be done.

Bibliography

1. Meier, R., "Good Morning Cedar Rapids. Do You have Audio? Reflections on Teaching a University Distance Education Course", Proceedings of the 1997 American Society for Engineering Education Annual Conference and Exposition.

2. Bloom, B., Taxonomy of Educational Objectives; Handbook 1:Cognitive Domain, David McKay Co., NY, 1956.

3. Kellogg, R. and Vogel, J., "Engineering Design as a Learning Process", Proceedings of the 2001 American Society for Engineering Education Annual Conference and Exposition.

4. Felder, R., "Matters of Style", ASEE Prism, 6(4), 18-23 (December 1996).

5. Carnevale, D., "Engineering Accreditors Struggle to Set Standards for Online Lab Sessions", The Chronicle of Higher Education. http://www.chronicle.com/free/2002/02/2002020101u.htm (1 Feb. 2002).

6. “A Model for On-Line Learning Networks in Engineering Education”, Journal of Asynchronous Learning Networks, 1(1), p. 73-94.

7. University of Illinois, Mallard Website, http://www.cen.uiuc.edu/Mallard/, 2000.

8. Kashy, D., Albertelli, G., Kashy, E., Thoennessen, M., "Teaching with ALN Technology: Benefits and Costs", Journal of Engineering Education, 90(4), p. 499-506. 
RICHARD W FREEMAN

Richard W Freeman is an adjunct instructor in the Department of Electrical and Computer Engineering at ISU. He is also a faculty member working with the Leadership through Engineering Academic Diversity Program for ISU's College of Engineering. He is also a PhD candidate in Computer Engineering with research interests in learning community effectiveness and assessment, and engineering education.

\section{REBECCA SIDLER KELLOGG}

Rebecca Sidler Kellogg is the Director for Engineering Distance Education at Iowa State University (ISU). She is also an adjunct assistant professor in Aerospace Engineering and Engineering Mechanics at ISU. Her research interests include engineering design, learning and education in engineering, and learning environments appropriate for life learners. 